\title{
Editorial
}

\section{Brain drain and practice locations of Nepalese medical students}

\author{
Pathiyil Ravi Shankar \\ Editor, JMCJMS
}

In the last three decades Nepal has been producing a substantial number of doctors predominantly in private medical schools. A recent newspaper article mentions that about 2000 doctors are being produced annually in Nepal. Assuming that the number of Nepalese students in different medical colleges in the country at a conservative $30 \%$, this translates into nearly 600 doctors being produced. Recent statistics from Graph Nepal puts the total number of doctors in Nepal at 16432 and over $67 \%$ of them were male [1]. The doctor to population ratio for the whole country is $1: 1724$. Like most developing nations, doctors are geographically maldistributed in Nepal. The Kathmandu valley has one doctor for 850 people but in rural areas the number is one doctor for every 150000 people [2]. The doctor-population density in Kathmandu is estimated to be about 40 times that in rural Nepal [3].

\section{Migration to developed nations:}

A large percentage of medical graduates and doctors from Nepal migrate to developed nations. A study showed that in 2004, the emigration rate was $9 \%$ and over $50 \%$ of graduates of the Institute of Medicine (IoM) during the period 2003-04 migrated [4]. The largest percentage migrated to the United
States of America (USA) followed by the United Kingdom (UK). The factors influencing doctor migration can be divided into 'push' factors operating in Nepal and 'pull' factors working in the developed recipient country. Less employment opportunities for doctors, differences in salary, fewer opportunities for professional development, political instability, corruption, fear of placement in remote areas, lack of workplace security were among the 'push' factors cited [4,5]. Among the major 'pull' factors were equal opportunities regardless of demographics, good living standard, job security, stable future for self and family, increasing access to the global labor market and peer group influence.

\section{Attracting and retaining doctors in rural Nepal:}

The issues surrounding attracting and retaining doctors in rural Nepal have also been discussed in the literature. In Nepal, the Ministry of Health and Population (MoHP) has implemented a compulsory two year rural service for all the scholarship holders of the Ministry of Education [6]. The consideration provided to these students for postgraduate seats at the National Academy of Medical Sciences (NAMS) is a strong 
motivating factor for rural service. Patan Academy of Health Sciences (PAHS) was established with the goal of addressing the health manpower imbalance in rural Nepal. Among the unique features of the program at PAHS are rural community participation in curriculum design, their participation in the student selection process, their help in creating rural educational platforms, supporting the teaching-learning process and assessment, and also in creating enabling environments for recruitment and retention [7]. The emphasis at present in Nepal with regard to rural service has been mainly on doctors who have just graduated doing a period of rural service as part of graduation requirements with the incentive of preference for post graduation.

\section{Working in rural Nepal:}

Student perception about working in rural Nepal after graduation has been studied among various cohorts of students. A study was conducted among first and second year medical students at a private medical school in the Kathmandu valley [8]. Nearly $73 \%$ of respondents were in favor of working in rural Nepal after graduation. Inadequate facilities, security concerns, low salary, problems with professional development, decreased contact with family, lack of equipment in rural health facilities and difficulties in communicating with a rural population were cited. Nearly half the respondents felt their medical training does not adequately prepare them for rural practice.

A study conducted among final year medical students and doctors doing their internship examined the factors influencing the choice of urban or rural location for future practice [9]. Rural location of rearing and of secondary education was found to be significant predictors of rural practice. Another study found that $88 \%$ of the 469 medical students who participated indicated that they would practice in Nepal after graduation but $88 \%$ also mentioned it likely that they would practice in urban areas [10]. Students more likely to practice in rural Nepal were male, had attended a government secondary school, were born in a rural area and had received a scholarship that requires rural service. The authors suggest that medical schools consider selecting students from rural areas and from government secondary schools.

A retrospective study examined graduates of the first 22 batches of IoM, the first medical school in the country [11]. Of the 710 graduates located, $27.2 \%$ were working in Nepal in districts outside Kathmandu, 36.8\% were working in Kathmandu and 36.1\% were working in foreign countries with the US being the most common location. The authors found that those with premedical education as paramedics, academically weaker students, older age at matriculation and a rural birthplace were more likely to be working in rural Nepal.

\section{Requirements for ECFMG certifications after 2023:}

Due to better job prospects and significantly higher remuneration in developed nations, migration of doctors and other health personnel from Nepal may continue. One factor which may impact this migration is the requirement by the US Educational Commission for Foreign Medical Graduates (ECFMG) that for registration after 2023, doctors must graduate from a medical school which has been properly accredited [12]. The medical school must be accredited through a formal process which uses criteria comparable to those used by the US Liaison 
Committee on Medical Education (LCME) or uses globally accepted criteria like those put forward by the World Federation for Medical Education (WFME). The Nepal Medical Council (NMC) which accredits Nepalese medical schools will have to use a process which is in accordance with WFME standards. Latest data from WFME shows that the accrediting agencies which are recognized as of September 2017 are the Accreditation Commission on College of Medicine (ACCM), Caribbean Accreditation Authority for education in Medicine and other Health Professions (CAAM-HP), The Association for Evaluation and Accreditation of Medical Education Programs (TEPDAD) from Turkey, Committee on Accreditation of Canadian Medical Schools, LCME, Korean Institute of Medical Education and Evaluation (KIMEE) and Japan Accreditation Council for Medical Education (JACME).

\section{Benefits for developed recipient nations:}

Developed English speaking nations have not discouraged and in many cases have encouraged the migration of health professionals. In the United Kingdom (UK), $31 \%$ of practicing doctors were born outside the country [13] and educating a doctor in the UK costs between 200000 to 250000 British pounds and the migrating doctor may in effect be importing this sum into the UK [14]. In 2005, international medical graduates (IMGs) constituted between 23 and 28\% of physicians in the US, UK, Canada and Australia [15]. Lower income countries supply between 40 to $75 \%$ of IMGs. Many developed nations are taking steps to increase the number of physicians produced within their borders, though it is likely that demand will continue to outstrip supply for many more years.

\section{Utilizing the Nepalese health diaspora:}

Nepal could utilize the skills, knowledge and expertise of the doctor/health worker diaspora settled abroad. A recent study mentions that the diaspora support health in Nepal in two main ways: the first was through financial contribution while the second was through their knowledge, technical skills and connections in their country of residence [16]. Nepalese diaspora get involved with health services in Nepal in three main ways, through diaspora volunteering organizations, through non-resident Nepalese associations and through their own connections to their place of origin. Involving the diaspora in medical services, research, education and training in Nepal can help in converting the 'brain drain' being experienced into 'brain circulation'.

The challenges for Nepal are to get more doctors to practice in rural areas and also to reduce the doctor migration and motivate more doctors to stay in the country. Doctors who migrated should be encouraged to establish links with the Nepalese health and medical educations system for mutual benefit. A variety of measures to ensure adequate number of doctors in rural Nepal, some of which have been used in other countries and described in the literature can and are being used toward this end.

\section{REFERENCES}

1. Graph Nepal. Number of doctors in Nepal (1960-2015). [Cited November 18, 2017]. Available from http://graphnepal.com/number-of-doctors-in-nepal/.

2. Patan Academy of Health Sciences. Nepal at a glance. [Cited November 18, 2017]. Available from: http://www.pahs.edu.np/about/about-nepal/.

3. Ailuogwemhe J, Rajbhandari R, Iliaki E, Villar M, Dieterich M. Tackling shortages of health care workers in rural Nepal: "Train to Retain". Harvard School of Public Health, Student Project, ID 262: Introduction to the Practice of International Public Health; 2005. 
4. Phuyel BD. Doctor's brain drain in Nepal: exploring the patterns, causes, consequences and solutions. July 2013. Available from: http://www.pp.utokyo.ac.jp/grasppold/courses/2013/documents/5140143 2a.pdf.

5. Sapkota TN, van Tiejlingen E, Simkhada PP. Nepalese health workers' migration to the United Kingdom: a qualitative study. Health Science Journal 2014;8:57-74.

6. Sitaula S, Magar A. Medical practice in the peripheral health centers in Nepal. J Nepal Health Res Counc. 2011;9:198-200.

7. Baral K, Allison J, Upadhyay S, Bhandary S, Shrestha S, Renouf $\mathrm{T}$. Rural Community as Context and Teacher for Health Professions Education._Cureus. 2016; 8: e866.

8. Shankar PR, Thapa TP. Student perception about working in rural Nepal after $g$ raduation: a study among first- and secondyear medical students. Hum Resour Health. 2012; 10: 27.

9. Sapkota BP, Amatya A. What factors influence the choice of urban or rural location for future practice of Nepalese medical students? A cross-sectional descriptive study. Hum Resour Health. 2015; 13: 84.

10. Huntington $\quad I^{1}$, Shrestha S, Reich NG, Hagopian A. Career intentions of medical students in the setting of Nepal's rapidly expanding private medical education system. Health Policy Plan. 2012; 27: 417428.

11. Zimmerman M, Shakya R, Pokhrel BM, Eyal N, Rijal BP, Shrestha RN, Sayami A. Medical students' characteristics as predictors of career practice location: retrospective cohortstudy tracking gr aduates of Nepal's first medical college. BMJ. 2012; 345: e4826.

12. Educational Commission for Foreign Medical Graduates. Medical school accreditation requirement for ECFMG certification. [Accessed 8th September 2017]. Available from: http://www.ecfmg.org/about/initiatives-accreditationrequirement.html.

13. Pang T, Lansang MA, Haines A. Brain drain and health professionals. BMJ. 2002; 324: 499-500.

14. Eastwood JB, Conroy RE, Naicker S, West PA, Tutt RC, Plange-Rhule Loss of health professionals from sub Saharan Africa: the pivotal role of the UK. Lancet. 2005; 365: 18931900.

15. Mullan F. The metrics of the physician brain drain. $\mathrm{N}$ Engl J Med 2005; 353: 1810-1818.

16. Devkota A, Devkota B, Ghimire J, Mahato RK, Gupta RP, Hada in the health sector in Nepal. J Nepal Health Res Counc. 2013;11:119-125.

\section{Correspondence to:}

Prof. Dr. Pathiyil Ravi Shankar

Associate Dean

American International Medical University

Gros Islet, Saint Lucia

E-mail: ravi.dr.shankar@gmail.com 